\title{
Calculating the Human Mutation Rate by Using a NUMT from the Early Oligocene.
}

\author{
Ian Logan'
}

\begin{abstract}
As the number of whole genomes available for study increases, so also does the opportunity to find unsuspected features hidden within our genetic code. One such feature allows for an estimate of the Human Mutation Rate in human chromosomes to be made. A NUMT is a small fragment of the mitochondrial DNA that enters the nucleus of a cell, gets captured by a chromosome and thereafter passed on from generation to generation. Over the millions of years of evolution, this unexpected phenomenon has happened many times. But it is usually very difficult to be able to say just when a NUMT might have been created. However, this paper presents evidence to show that for one particular NUMT the date of formation was around 29 million ago, which places the event in the Early Oligocene; when our ancestors were small monkey-like creatures. So now all of us carry this NUMT in each of our cells as do Old World Monkeys, the Great Apes and our nearest relations, the Chimpanzees. The estimate of the Human Mutation obtained by the method outlined here gives a value which is higher than has been generally found; but this new value perhaps only applies to non-coding regions of the Human genome where there is little, if any, selection pressure against new mutations.
\end{abstract}

'Exmouth, Devon UK

Email: ianlogan22@btinternet.com

\section{INTRODUCTION}

In the last few years an increasing number of primate species have had their genomes sequenced and the results placed in the Public Domain. The first genome was produced by the Human Genome Project, and now there are genomes for 15 species of Primate available for study at

http://www.ncbi.nlm.nih.gov/mapview/

The activity of examining a genome for a particular purpose has been described as data mining (Yao 2009); and there is no doubt that many interesting features of our DNA are yet to be found. The human genome contains the coding for about
20,000 active genes and this accounts for under a half of the DNA in the chromosomes, with the remainder being non-coding; and it is the data mining of the non-coding regions that is likely to yield the greatest surprises. In this paper a particular non-coding region is examined with the purpose of calculating the Human Mutation Rate.

Lipson et al. (2015) in their recent paper reviewed the importance of calculating the Human Mutation Rate and suggested 4 methods that can be used in its determination. The methods were described in simple terms: [1] comparing corresponding DNA sequences DNA from different modern day species and counting the mutations that have occurred over an estimated period of 
time; [2] comparing genomes from related modern day people and counting the observed differences; [3] comparing a modern day genome to an archaic genome, for example from a Neandertal or a Denisovan; and [4] a mathematical method termed Ancestral recombination Density.

These 4 methods give a Human Mutation rate $(\mu)$ in the region of:

$\mu=1-2.5 \times 10^{-8}$ per base per generation (using 29 years as a generation)

But what does this really mean?

And, a simpler concept might be to consider the percentage change in a DNA sequence, making $\mu$ as described above equivalent to;

On average, $1-2.5 \%$ of the bases mutate in a period of 29 million years

This Human Mutation Rate is assumed to apply to the total DNA of the chromosomes, however coding DNA can be assumed to mutate at a much slower rate than non-coding DNA because of selection - with harmful mutations being selected against. Whereas, the mutation rate in a non-coding sequence has no such restriction and the mutation rate will be much higher.

In this paper a non-coding sequence, a mitochondrial NUMT, is described and used to calculate the Human Mutation rate as it applies to Chromosome 8; with the result being that a value for $\mu$ is found that is higher than previously described.

\section{Mitochondrial DNA}

In every cell of the body as it is formed there is a nucleus, containing 23 pairs of chromosomes, and in the cytoplasm are the mitochondria. These are small structures associated with the production and transfer of energy within the cell and they contain short DNA molecules- the mitochondrial DNA (mtDNA). These molecules contain about 16,569 bases and in a person most of mtDNA molecules will be identical. The bases of the mtDNA can be considered as being numbered and their state $(A, C, G$ or $T)$ is usually described compared to the Cambridge Reference Sequence (CRS). (Anderson 1981, Andrews 1999)

The bases in the mtDNA do have a high mutation rate, much greater than that of the chromosomal DNA, with roughly 50 mutations having occurred in the last 200,000 years. Mutations can occur in all parts of the mtDNA, but there is selection against overtly harmful mutations being propagated, with the result that about 5 times as many mutations are observed in non-coding areas as opposed to coding areas. (Logan, 2007, Behar 2012)

The structure of the mtDNA has been extensively studied and in each molecule there is coding for 13 genes, 2 RNA molecules, and 22 tRNAs and sequences associated with the production of further mitochondria - such as the 'OriL' sequence concerned with the replication of the light strand. Also, and of importance in respect to this paper, are a number of non-coding sequences interspersed between the functional coding sequences.

In this paper the area of the mtDNA from base 5097 to base 7195 is of special interest and corresponds to: 2 incomplete genes (MT-ND2 \& MT-CO1), 5 tRNAs (for the amino acids Tryptophan, Alanine, Asparagine, Cysteine \& Tyrosine), the OriL region, and 3 noncoding regions. Table 1 shows this area of the mtDNA in some detail. 
Table 1: The parts of the mtDNA (CRS) for the region of interest (bases 5097-7195)

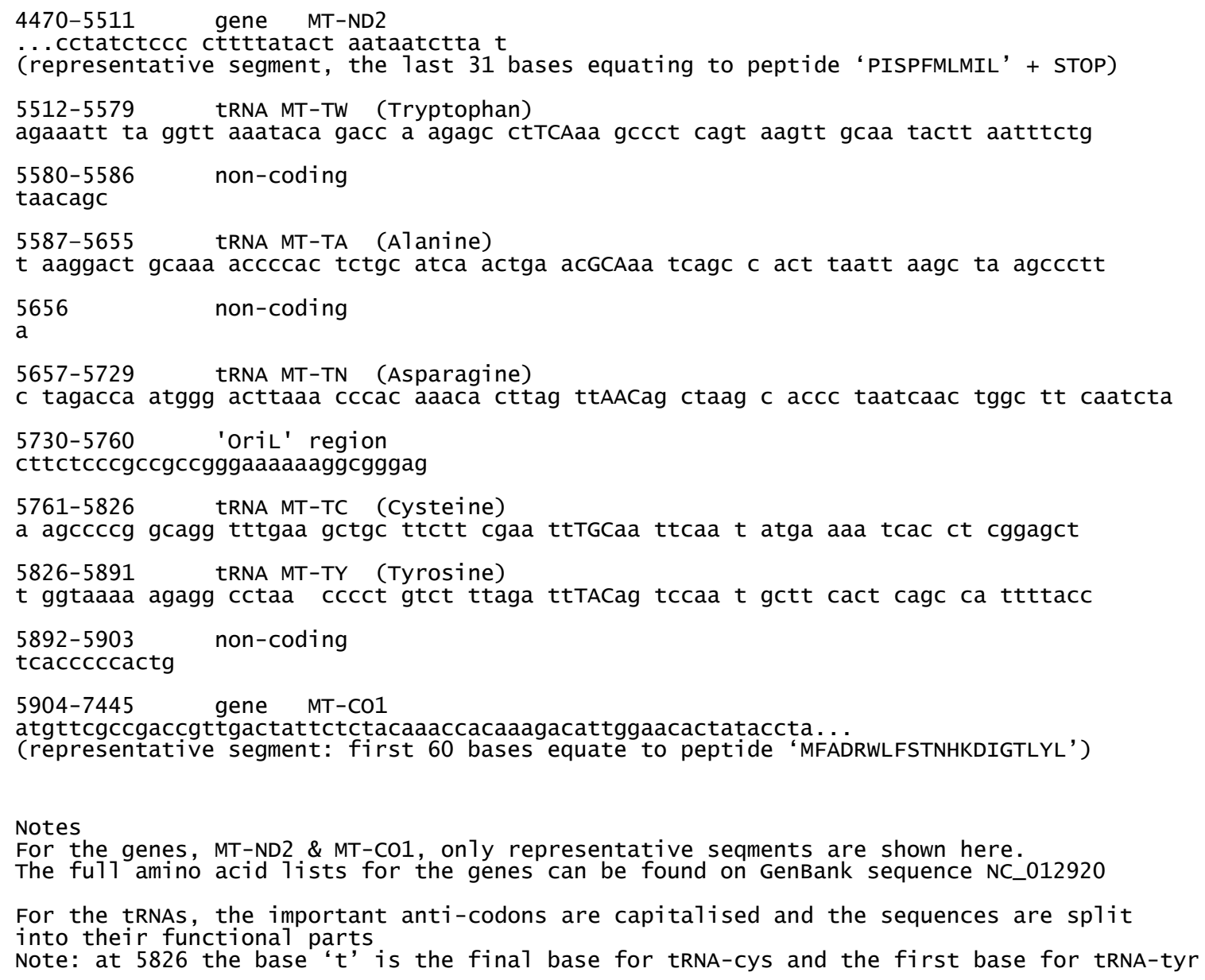

\section{NUMT (NUclear MiTochondrial DNA)}

A NUMT (pronounced as 'new-might') is a fragment of the mitochondrial DNA (mtDNA) that has become incorporated into a chromosome. Initially, it was thought this type of capture was an uncommon occurrence, but now it is suspected that the formation of NUMTs has occurred in all species and, although infrequent, is an ongoing process.

(Selected references: Herrnstadt 2009, Bensasson 2003, Hazkani-Covo 2008, Logan 2009, Simone 2011, Calabrese 2012)

Recently, a paper detailed a number of NUMTs that are to be found in the people from different populations around the world, showing that the formation of these NUMTs date to less than 200 thousand years. (Dayama 2014)
By the very nature of the method of its formation, a NUMT shows several random features:

Firstly, the fragment separated from the mtDNA can be small or large. However, in most instances it is not possible to data mine for small NUMTs, perhaps of less than 50 bases in length, but with increasing size the searching becomes easier. Now, over a thousand NUMTs have been identified in the Human genome.

Secondly, the actual chromosome capturing a NUMT appears to another random event. However, the number of NUMTs in a given chromosome is closely related to the overall size of the chromosome, with the largest, chromosome 1, having a considerable number of NUMTs. 
Thirdly, the position of a NUMT within a chromosome again appears to be essentially random. However, there are reports describing NUMTs that have interfered with gene coding regions and caused disease. (Reviewed by HazkaniCovo 2010)

Fourthly, the bases in a NUMT can themselves mutate over the generations, and as with any other mutation in a noncoding region there is unlikely to be selection against a mutation in a NUMT.

Fifthly, there is the question of age determination. A NUMT that has a sequence that closely matches a modern mtDNA sequence can be considered to be of recent origin. So if a NUMT shows almost total concordance it is likely to have been formed within, say, the last 5 million years. But if the match is as poor as $75 \%$ concordance, such a NUMT might have been formed, say, 30 million years ago. Unfortunately, it is not possible to ascertain the exact age of a given NUMT and there will always be a degree of uncertainty over any age that is suggested.

And, finally, there is the feature of interspecies conservation. A Human NUMT with an age of formation of more than, say, 6 million years is likely to be found in the genome of our closest relative, the Chimpanzee. And, with a Human NUMT formed, say, 30 million years ago, it might expected to be found in all the genomes of the Old World Monkeys, the Great Apes, and, of course, Homo sapiens.

\section{The Primate Evolutionary Tree (See Figure 1)}

The exact dates involved in the Primate Evolutionary tree are uncertain, but the details in Figure 1 are probably reasonable. (Finstermeier 2013, Pozzi 2014)

To summarise, the figure shows modern day man as having separated from:

- the Chimpanzee and Bonobo around 6 million years ago

- the Great Apes (i.e. the Gorilla, Orangutan, and Gibbon) around 20 million years ago

- the Old World Monkeys (i.e. the Macaques and the Green monkey) around 25-30 million years ago.

- and the New World Monkeys and the earliest Primates

(i.e. the Golden snub-nosed monkey, the Bolivian Squirrel Monkey,

the White-tufted-ear marmoset, the Philippine tarsier and the Small-eared galago)

more than 30 million years ago.

In this paper the period of 29 million years will be used to describe the separation between modern day man and the Green monkey solely because this figure allows the separation to be considered as having occurred 1 million generations ago. 


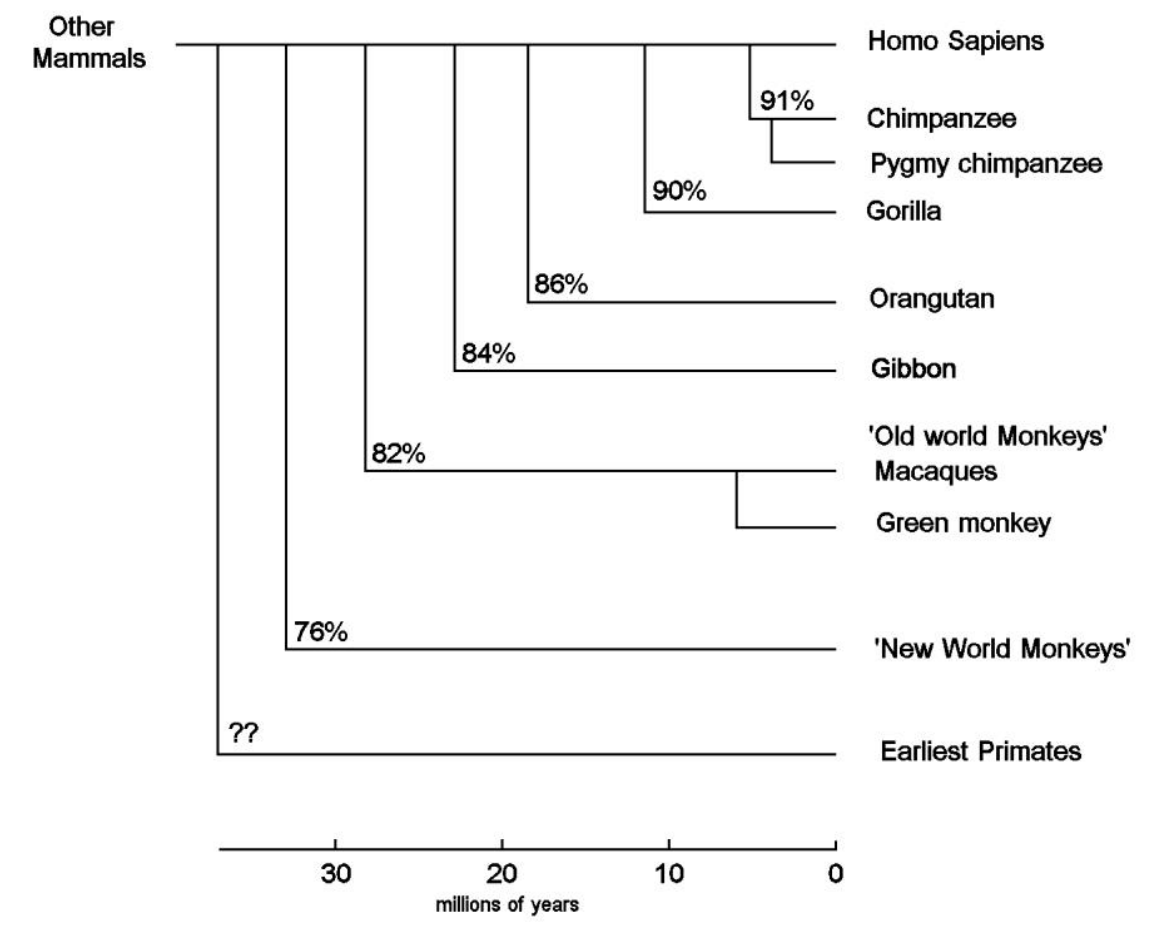

Figure 1: The Primate Evolutionary Tree

The horizontal scale is measured in millions of years.

The percentages show the mtDNA relatedness.

\section{Materials and methods}

This paper identifies a selected region of Chromosome 8 as being a NUMT; and uses 4 DNA sequences as evidence to support this hypothesis.

The sequences are all obtainable from the NCBI's GenBank database.

The first sequence shows the region of the Human mtDNA sequence, the CRS, from bases 5097-7195. Details of how to obtain this sequence, and the 3 other sequences, is given in a step-by-step guide as part of the supplementary material.

The parts of this region of the first sequence are listed in table 1.

The second sequence is the presumed NUMT, from chromosome 8 , coordinates 110933244-110935358 This NUMT has been also classified as HSA_NumtS_32 1 by Calabrese (2012).
It is to be noted that there are several NUMTs in the Human genome that match the CRS region 5097-7195. But there does appear to be only a single NUMT from chromosome 8.

The third and fourth sequences are the corresponding mtDNA and NUMT sequences from the genome of the Green monkey (Chlorocebus sabaeus).

For the purposes of this paper the genome of the Green monkey has been chosen, and the appropriate details provided, because it is the genome of a species which is the most distant in evolutionary terms from Homo sapiens and yet still shows the same NUMT. The genomes of the Rhesus macaque or the Crab-eating macaque would serve just as well.

Also, for clarity, a few bases at ends of the NUMT have not been selected as the bases do appear to vary between one genome and another. 
The hypothesis suggested in this paper is firstly, that a NUMT corresponding to the mtDNA region 5097-7195 exists and can be found on Chromosome 8, and secondly it is suggested that this NUMT was formed about 29 million years ago. And, In order to support the two parts of the hypothesis 4 DNA sequences have been obtained from the GenBank database.

The first sequence comes from the mitochondrial genome of the Human, as represented by the CRS. The sequence contains the coding for parts of 2 genes, 5 tRNAs, the 'Oril' region, together with 3 non-coding regions.

The second sequence is from a region of Chromosome 8 and this is shown to be a NUMT as the sequence can be mapped against the first sequence without difficulty.

Table 2 shows the mapping of the CRS sequence against the NUMT and shows that all the different functional parts present in the CRS sequence can be demonstrated in the NUMT.

The third and fourth sequences repeat the above process, but this time using sequences from the genome of the Green Monkey.

Once again Table 2 shows how the 4 sequences map against each other in respect of all the different functional parts.

It is interesting to note that both the NUMT from the Human genome and that from the genome of the Green monkey have the same insertion of 16 bases in the tRNA sequence for the amino acid, Cysteine.
The presence of NUMTs that match each other and are found in the genomes of 2 species of primate that are considered to have separated from each other around 29 million years ago, does suggest that this NUMT was indeed formed at the time of separation, and in the Early Oligocene.

Whilst all the sequences map against each other, there are mutational differences between the sequences and the number of observable mutations is crucial to the estimation of the Human Mutation Rate.

And,

http://www.ncbi.nlm.nih.gov/mapview/ and BLAST (Altschul 1990) can be used to show that the correspondence between the Human NUMT sequence and that of the modern Human mtDNA sequence is about $76 \%$, or putting it another way, about $24 \%$ of the bases of the NUMT show mutations. However, this method of comparing a NUMT sequence from a chromosome with a modern mtDNA sequence gives a very high figure as the mutation rate in mitochondrial DNA is very much higher than in chromosomal DNA.

But it is possible to calculate the Human Mutational Rate by considering the mutational changes that show as differences in the DNA sequences of the two NUMTs from the Human and the Green monkey. This method looks for the mutations that have occurred over a period of 29 million years in both species and therefore half the number of differences can be assumed to have occurred in just one NUMT.

The number of differences between the 2 NUMTs is approximately $7.6 \%$

(150 base mutations and 14 small insertions/deletions in the 2,115 bases) which suggests a Mutation Rate value of $\mu=3.8 \times 10^{-8}$ per base per generation. 


\section{Table 2: The 4 sequences compared}

TRNA MT-TW

1. CRS agaaatt ta ggtt aaataca gacc a agagc ctTCAaa gccct cagt aagtt gcaa tactt aatttctg

2. NUMT agaaatt ta ggtt aaataa gacc a atggc ctTCAaa gcctt tagc aagtaa atta tactt aatttctg

3. Green agaaatt ta ggtt aaataa gacc a agagc ctTCAaa gccct tagt aagt agac cact aatttctg

4. NUMT agaaatt ca ggtt aaatga gacc a atggc ctTCAa gcctt tagc aagtaa atta tact catttctg

Non-coding

1. CRS taacagc

2. NUMT caacaaacc

3. Green aacata

4. NUMT caacaaagc

TRNA MT-TA

1. CRS $t$ aaggact gcaaa accccac tctgc atca actga acGCAaa tcagc c act taatt aagc ta agccctt

2. NUMT $t$ aaggact gcaag actccac tctgc atca attga acGCAaa tcaac $t$ act ttaatt aagc ta agccctc

3. Green $t$ aaggact gcaaa aacctac tctgc atca attga acGCAaa tcaac c act ttaatt aagc ta agcccct

4. NUMT t aaggact gcaaa actccac tctgc atca attga acGCAaa tcaac c act ttaatt aagc ta agccctc

Non-coding

1. CRS a

2. NUMT $t$

3. Green a

4. NUMT g

TRNA MT-TN

1. CRS c tagacca atggg acttaaa cccac aaaca cttag ttAACag ctaag c accc taatcaac tggc tt caatcta

2. NUMT C tagattg gtgga attaaac ccacg aaa-a tttag ttAACag ctaaa c accc taatcaag tggc tt caatcta

3. Green c tagacca atggg actcaaa cccat aaaaa tttag ttAACag ctaaa c accc taatcaac tggc tt tgatcca

4. NUMT C tagcttg atgga attaaac ccacg aaa-a tttag ttAACag ctaaa c accc taatcaac tggc tt caatctg

oriL

1. CRS cttctcccgccgccgggaaaaaaggcgggag

2. NUMT cttctcccgccgctgggaaaaaaggcgggag

3. Green cttctcccgccacgagaaaaaaaggcgggag

4. NUMT cttctccaacgctgggaaaaaaggcgggag

tRNA MT-TC

1. CRS

a agccceg gcagg tttgaa --gctgc ttctt cgaa --------------- ttTGCaa ttcaa t atga aaa tcac ct cggagct

2. NUMT

a agccctg gcagg agtgaa --gctgc tcctt tgaa cttagtctgaattttca tgTTGaa ttcaa c atga aaa tcac ct cgggact

3. Green

a agccccg gcaga aactta aaactgc tcctt taaa --------------- ctTGCaa tttaa c atga aaa tcac ct cggggct

4. NUMT

a agccccg gcagg attgaa --gctgc tcctt tgaa cttcgtctgcattttca tgTTGaa ttcaa c atga aaa tcac ct tgggact

TRNA MT-TY

1. CRS t ggtaaaa agagg cctaa cccct gtct ttaga ttTACag tccaa $t$ gctt cact cagc ca ttttacc

2. NUMT t ggtaaaa agagg ccttaa cctcc atct tcaga ttTGCag tctaa t gtt -act cagc ca ttttacc

3. Green $t$ ggcaaaa agagg atcaga cctct gtct tcagg ttTACag cctaa $t$ gctt -act cagc ca ttttacc

4. NUMT t ggtgaaa agagg ccttaa cttc tgtct ttaga ttTACag tttaa $t$ gctt -act cagc ca ttttacc

Non-coding

1. CRS tcacccccactg

2. NUMT tttttcactccactt

3. Green cttcctccaccc

4. NUMT ttttcactccactt

Gene MT-CO1 (representative first 60 bases shown here)

1. CRS atgttcgccgaccgttgactattctctacaaaccacaaagacattggaacactataccta =

2. NUMT atgttcatcaaccgttgattgttttcaagcaaccacaaagacatgggaacattatagtta =

3. Green atgttcattaatcgttgactcttttcaacaaaccataaagacatcggaactctataccta =

4. NUMT acgttcatcaaccgttgattgttttcagctaaccacaaagacattgcaacatcatactta

'MFADRWLFSTNHKDIGTLYL'

'MFINRWLFSSNHKDMGTL $\angle S T O P>L$ '

'MFINRWLFSTNHKDIGTLYL'

'TFINRWLFSANHKDIATSYL'

The 4 sequences are:

1. The CRS mtDNA sequence

2. The Human NUMT from Chromosome 8

3. The mtDNA from the Green monkey genome

4. The Green monkey NUMT from chromosome 8 


\section{Discussion}

The claim to being able to calculate the Human Mutation Rate by using a new method has to be justified carefully.

In this study the existence of a NUMT corresponding to a substantial part of the mtDNA molecule has been shown. The NUMT found on Chromosome 8 is over 2,100 bases in length and maps against the mtDNA sequence of modern day man, using the CRS as the example, in respect of gene coding, multiple tRNA coding, the special OriL region, as well as several distinctively sized non-coding regions. Repeating the process with the genome of our distant relative the Green monkey also shows that the same NUMT is to be found on its chromosome 8 . This NUMT from a distantly related species also shows the same distinctive features, which strongly suggest the common origin of both NUMTs in a single event; and the subsequent conservation in the two species.

The method therefore can be considered as showing that the original NUMT was formed around 29 million years ago. (This figure used as it represents 1 million generations.) But there has to be considerable uncertainty over this figure and even to use the wide range of $+/-5$ million years might not be unreasonable.

Also, there is the question of whether it is reasonable to compare the NUMT from the modern Human mtDNA sequence against the NUMT from the Green monkey to obtain a measure of the Human Mutation Rate. Clearly, bases within the NUMT will have mutated since its formation, and it appears that perhaps $7.6 \%$ of them have perhaps done so. This figure shows the mutations that have occurred in both NUMTs and therefore the figure has to be halved to obtain the Mutation Rate as it applies just to the Human.
For the above reasons, a suggested value of $\mu=3.8 \times 10^{-8}$ per base per generation must be considered as having a wide margin of uncertainty, although it is hard to believe the rate would be higher. Therefore, it is perhaps best to consider that this new method of calculating the Human Mutation Rate gives a value of $\mu=3-4 \times 10^{-8}$ per base per generation. This value is higher than previous estimates, and probably reflects that in purely non-coding DNA the mutation rate is high when there is little, if any, selection against mutations.

The paper tries to highlight the difficulties in obtaining a meaningful figure for the Human Mutation Rate when it is not possible to compare DNA sequences directly. The use of a NUMT, which is considered to a be 'fossilised' record of the mtDNA as it was at the time of the formation of the NUMT is an attempt to obtain an archaic sequence which can then be compared to a modern day sequence. This method does perhaps resolve some of the problems used in other methods (as reviewed by Lipson 2015).

Also, there is the question as to whether the term 'Human Mutation Rate' can be considered to refer to a single quantity. Or, is there one figure for coding regions, another for non-coding regions, and a third overall figure. In this paper the suggested Human Mutation Rate applies only to non-coding regions.

And, is it reasonable to use a figure of 29 years per generation when considering mutations that have occurred since the Oligocene in the Human ancestral line and that of the Green monkey.

Overall the method does give a useful value for the Human Mutation Rate that can be compared to that obtained by other methods. 
bioRxiv preprint doi: https://doi.org/10.1101/016428; this version posted March 14, 2015. The copyright holder for this preprint (which was not certified by peer review) is the author/funder, who has granted bioRxiv a license to display the preprint in perpetuity. It is made available under aCC-BY-ND 4.0 International license.

References:

Altschul, S. F., W. Gish, W. Miller, E. W.

Myers, and D. J. Lipman. (1990)

Basic local alignment search tool

J. Mol. Biol. 21 5:403-410.

Anderson S, Bankier AT, Barrell BG, de Bruijn $\mathrm{MH}$, Coulson AR, Drouin J,

Eperon IC, Nierlich DP, Roe BA, Sanger F, Schreier PH, Smith AJ, Staden R,

Young IG. (1981)

Sequence and organization of the human mitochondrial genome.

Nature Apr 9;290(5806):457-65.

Andrews RM, Kubacka I, Chinnery PF, Lightowlers RN, Turnbull DM, Howell N. (1999)

Reanalysis and revision of the Cambridge reference sequence for human

mitochondrial DNA.

Nat Genet. Oct;23(2):147.

Behar DM, van Oven M, Rosset S, Metspalu M, Loogväli EL, Silva NM, Kivisild T, Torroni A, Villems R. (2012)

$A$ "Copernican" reassessment of the human mitochondrial DNA tree from its root.

Am J Hum Genet. Apr 6;90(4):675-84.

Calabrese FM, Simone D, Attimonelli M.(2012)

Primates and mouse NumtS in the UCSC Genome Browser.

BMC Bioinformatics. Mar 28;13

Dayama G, Emery SB, Kidd JM, Mills RE. (2014)

The genomic landscape of polymorphic human nuclear mitochondrial insertions Nucleic Acids Res.

Nov 10;42(20): 12640-9

Douda Bensasson, Marcus W. Feldman, Dmitri A. Petrov (2003)

Rates of DNA Duplication and

Mitochondrial DNA Insertion in the Human Genome

J Mol Evol 57:343-354
Francesco Maria Calabrese, Domenico Simone, Marcella Attimonelli. (2012)

Primates and mouse NumtS in the UCSC Genome Browser

BMC Bioinformatics 13(Suppl 4):S1 5.

Finstermeier K, Zinner D, Brameier M, Meyer M, Kreuz E, et al. (2013)

A Mitogenomic Phylogeny of Living Primates

PLOS ONE 8(7)

Hazkani-Covo E, Covo S (2008)

Numt-Mediated Double-Strand Break

Repair Mitigates Deletions during Primate

Genome Evolution

PLoS Genet 4(10)

Einat Hazkani-Covo, Raymond M. Zeller, and William Martin (2010)

Molecular Poltergeists: Mitochondrial

DNA Copies (numts) in Sequenced

Nuclear Genomes

PLoS Genet. Feb; 6(2)

Herrnstadt C, Clevenger W, Ghosh SS, Anderson C, Fahy E, Miller S, Howell N, Davis RE.(1999)

A novel mitochondrial DNA-like sequence in the human nuclear genome

Genomics. Aug 15;60(1):67-77.

Mark Lipson, Po-Ru Loh, Sriram

Sankararaman, Nick Patterson, Bonnie

Berger, David Reich (2015)

Calibrating the Human Mutation Rate via

Ancestral Recombination Density in

Diploid Genomes

http://dx.doi.org/10.1101/015560

Logan, I (2007)

A Suggested Mitochondrial Genome for 'Mitochondrial Eve'

JoGG 3(2):72-77

Available at:

http://www.jogg.info/32/logan.pdf

Logan, I (2009)

The Continuing Hunt for Nuclear

Mitochondrial DNA sequences (NUMTs)

in the Human Genome

JoGG 5(1):23-34 Available at:

http://www.jogg.info/51/files/

LoganNUMT.pdf 
Pozzi L, Hodgson JA, Burrell AS, Sterner

KN, Raaum RL, Disotell TR.(2014)

Primate phylogenetic relationships and divergence dates inferred from complete mitochondrial genomes.

Mol Phylogenet Evol. Jun;75:165-83.

Domenico Simone, Francesco Maria

Calabrese, Martin Lang, Giuseppe

Gasparre, Marcella Attimonelli (2011)

The reference human nuclear

mitochondrial sequences compilation

validated and implemented on the UCSC

genome browser

BMC Genomics. 2011 Oct 20;12:517

Yong-Gang Yao, Antonio Salas, Ian Logan, and Hans-Jürgen Bandelt (2009)

mtDNA Data Mining in GenBank Needs

Surveying

Am J Hum Genet. 2009 Dec 11; 85(6):

929-933. 
bioRxiv preprint doi: https://doi.org/10.1101/016428; this version posted March 14, 2015. The copyright holder for this preprint (which was not certified by peer review) is the author/funder, who has granted bioRxiv a license to display the preprint in perpetuity. It is made available under aCC-BY-ND 4.0 International license.

\section{Supplementary material:}

There are 2 parts to the supplementary material

Supplement: A

A step-by-step guide showing how to obtain the 4 sequences discussed in the paper.

Supplement: B

The 4 sequences identified in the paper given in FASTA format 
Supplement A:

A step-by-step guide showing how to obtain the 4 sequences discussed in the paper.

In order to keep the paper as simple as possible, the selection of sequences is restricted to just 4 sequences - all obtainable from the NCBI GenBank database.

The first sequence: Human mtDNA (CRS)

By using: http://www.ncbi.nlm.nih.gov/nuccore/NC_012920

With the Change region shown set from: $5097 \&$ to: 7195

Click on Update View

This gives sequence of 2099 bases from the Human mtDNA (CRS).

The second sequence: The Human NUMT

Open http://www.ncbi.nlm.nih.gov/mapview/

Following along the Homo sapiens line click on B (for BLAST)

Enter the first sequence into the box

Select Somewhat similar sequences (blastn)

Select BLAST

When the hits appear, select the NUMT for Chromosome 8

This shows the NUMT is to be found on sequence

NC_000008 coordinates 110933244-110935358

And can be fetched from:

http://www.ncbi.nlm.nih.gov/nuccore/NC_000008

Use Customize view \& show reverse complement

to get the matching orientation.

This gives the corresponding Human NUMT.

The third sequence: The Green Monkey mtDNA

Open http://www.ncbi.nlm.nih.gov/mapview/

Following along the line Chlorocebus sabaeus click on B (for BLAST)

And using the first sequence and blastn,

Shows the corresponding Green Monkey mtDNA sequence is located at:

NC_008066 5092-7190

And this sequence can be downloaded from:

http://www.ncbi.nlm.nih.gov/nuccore/NC_008066

The fourth sequence: The Green Monkey NUMT from Chromosome 8

This is obtainable from:

http://www.ncbi.nlm.nih.gov/mapview/

Following along the line Chlorocebus sabaeus click on B (for BLAST)

and inputting the second sequence and using blastn.

The NUMT is found on NC_023649 at $105641836-105643957$

And the sequence can be fetched from:

http://www.ncbi.nlm.nih.gov/nuccore/NC_023649

using from: 105641836 \& to: 105643957 and show reverse complement 
bioRxiv preprint doi: https://doi.org/10.1101/016428; this version posted March 14, 2015. The copyright holder for this preprint (which was not certified by peer review) is the author/funder, who has granted bioRxiv a license to display the preprint in perpetuity. It is made available under aCC-BY-ND 4.0 International license.

Supplement: $\mathrm{b}$ : The 4 sequences identified in the text listed as FASTA format.

1. The 2099 base sequence from the Human mtDNA 5097-7195 NC_012920

1 atcctaacta ctaccgcatt cctactactc aacttaaact ccagcaccac gaccctacta

61 ctatctcgca cctgaaacaa gctaacatga ctaacaccct taattccatc caccctcctc 121 tccctaggag gcctgccccc gctaaccggc tttttgccca aatgggccat tatcgaagaa 181 ttcacaaaaa acaatagcct catcatcccc accatcatag ccaccatcac cctccttaac 241 ctctacttct acctacgcct aatctactcc acctcaatca cactactcc catatctaac 301 aacgtaaaaa taaaatgaca gtttgaacat acaaaaccca ccccattcct ccccacactc 361 atcgccctta ccacgctact cctacctatc tcccctttta tactaataat cttatagaaa 421 tttaggttaa atacagacca agagccttca aagccctcag taagttgcaa tacttaattt 481 ctgtaacagc taaggactgc aaaaccccac tctgcatcaa ctgaacgcaa atcagccact 541 ttaattaagc taagccctta ctagaccaat gggacttaaa cccacaaaca cttagttaac 601 agctaagcac cctaatcaac tggcttcaat ctacttctcc cgccgccggg aaaaaaggcg 661 ggagaagccc cggcaggttt gaagctgctt cttcgaattt gcaattcaat atgaaaatca 721 cctcggagct ggtaaaaaga ggcctaacc ctgtctttag atttacagtc caatgcttca 781 ctcagccatt ttacctcacc cccactgatg ttcgccgacc gttgactatt ctctacaaac 841 cacaaagaca ttggaacact atacctatta ttcggcgcat gagctggagt cctaggcaca 901 gctctaagcc tccttattcg agccgagctg ggccagccag gcaaccttct aggtaacgac 961 cacatctaca acgttatcgt cacagcccat gcatttgtaa taatcttctt catagtaata 1021 cccatcataa tcggaggctt tggcaactga ctagttcccc taataatcgg tgcccccgat 1081 atggcgtttc cccgcataaa caacataagc ttctgactct tacctccctc tctcctactc 1141 ctgctcgcat ctgctatagt ggaggccgga gcaggaacag gttgaacagt ctaccctccc 1201 ttagcaggga actactccca ccctggagcc tccgtagacc taaccatctt ctccttacac 1261 ctagcaggtg tctcctctat cttaggggcc atcaatttca tcacaacaat tatcaatata 1321 aaaccccetg ccataaccca ataccaaacg cccctcttcg tctgatccgt cctaatcaca 1381 gcagtcctac ttctcctatc tctcccagtc ctagctgctg gcatcactat actactaaca 1441 gaccgcaacc tcaacaccac cttcttcgac cccgccggag gaggagaccc cattctatac 1501 caacacctat tctgattttt cggtcaccct gaagtttata ttcttatcct accaggcttc 1561 ggaataatct cccatattgt aacttactac tccggaaaaa aagaaccatt tggatacata 1621 ggtatggtct gagctatgat atcaattggc ttcctagggt ttatcgtgtg agcacaccat 1681 atatttacag taggaataga cgtagacaca cgagcatatt tcacctccgc taccataatc 1741 atcgctatcc ccaccggcgt caaagtattt agctgactcg ccacactcca cggaagcaat 1801 atgaaatgat ctgctgcagt gctctgagcc ctaggattca tctttctttt caccgtaggt 1861 ggcctgactg gcattgtatt agcaaactca tcactagaca tcgtactaca cgacacgtac 1921 tacgttgtag cccacttcca ctatgtccta tcaataggag ctgtatttgc catcatagga 1981 ggcttcattc actgatttcc cctattctca ggctacacc tagaccaaac ctacgccaaa 2041 atccatttca ctatcatatt catcggcgta aatctaactt tcttcccaca acactttct

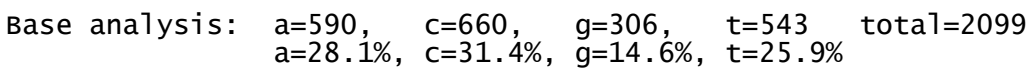

\section{The Human Chromosome 8 NUMT}

1 attctaacaa ttaccgcatt tcttacactc aatctgagca caagcactac aaccctatca

61 atattccaca cctgaaataa actaacatga ctaacaccta taattccatt aatttatta 121 tccctaggag gtttacccc attaatggga tttctcccta aatgagttac catccaagaa 181 cttacaaaa acaacagtct tattacccca accattatag atattataac cctactcaac 241 ctatactttt acacacgctt aatttactct acctcagtga caatattccc cacatctaat 301 aacataaaaa taaaatgacg gttcaaaaac acaaagtcca tattacccct cccccact 361 ataatctcta ccctcctctt acctatttct ccattaacac tatctatgat ctagaaatt 421 aggttaaata agaccaatgg ccttcaaagc ctttagcaag taaattatac ttaatttctg 481 caacaaacct aaggactgca agactccact ctgcatcaat tgaacgcaaa tcaactact 541 taattaagct aagccctctc tagattggtg gaattaaacc cacgaaaatt tagttaacag 601 ctaaacaccc taatcaagtg gcttcaatct acttctcccg ccgctgggaa aaaaggcggg 661 agaagccctg gcaggagtga agctgctcct ttgaacttag tctgaatttt catgttgaat 721 tcaacatgaa aatcacctcg ggactggtaa aaagaggcct taacctccat cttcagatt 781 gcagtctaat gtttactcag ccattttacc tttttcactc cacttatgtt catcaaccgt 841 tgattgtttt caagcaacca caaagacatg ggaacattat agttactatt ctgtgcatga 901 gcagggatag caggcacagc cttaagcctc cttattcaag cagaactggg ccaaccaggt 961 actctgctag aagatgatca aatttacaaa gttattgtta cctcccacgc atttatcata 1021 attttcttta tagttatacc aatcataatc ggaggttttg gcaactgatt agttcctctc 1081 ataattggct ctcctgatat ggcatttccc cgaataaata acgtgagttt ctgacttctc 1141 cctcccccc tttcctactg ttatttgcat tctcaatggt agaggctggc agtgggaccc 1201 gctggacagt ttatcctcc ttaacaggaa tcttaacatg caggatcctc tgtggacctg 1261 accatcttct cacttaattt agcaggcatc ttttctattc tagaagctat taattttact 1321 accacaatca ttaacatgaa tcccctggcc atatccetac atcacacacc cctcttcgtc 1381 tgatcagccc cagttacagc agttcttcta cttctttctc ttccagacct agccgccggc 1441 attactatgc tattaactga ctgtaatctc aacactacat tgtctgaccc agctgtcaga 1501 ggtgaccctg tcctgcatta acacttatct gattttttgg ccactctgaa gtctatgtcc 1561 ttatcttaca aggcttctgg ataatctccc acatcgtaac acactattct ggaaaaaagg 1621 aaccatttgt gtgcatgggc atagtatgag ccatagtatc agttggtttc ttaggattat 1681 catatgggct caccacatac ttacagtagg aatagatgta gatataggag catacttcac 1741 ctctgccact ataattattg ccctccccgc tggcatcaaa gtctttagtt ggttagcttc 1801 actacatggc agcaacatca aatgatcccc cacaattctt tgagccctgg gatttatatc 1861 ccctttaca ttaggaggtc tgaccggcat tgtactagct aactcatcac tagacattgt 1921 cttgcatgac acatattatg ttgtagctca tttccattac atcttatcag taggagccgt 1981 atttgctatt ataggaggct ttgtccactg atttccccta ttctcaggtt atatacttag 2041 tcagacctat gctaaaattc acttttccat catgtttata ggtgttaatt tgactttttt 2101 cccacagcat ttcct

Notes:

Base analysis (excluding the insertion 'cttagtctgaattttca')

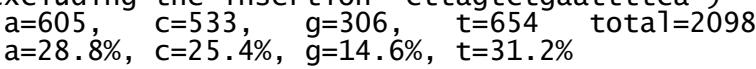

Chromosome coordinates: GRCh38/Hg38 110933244-110935358 GRCh37/Hg19 111945473-111947587

And described as HSA_NumtS_321 by Calabrese(2012) 
bioRxiv preprint doi: https://doi.org/10.1101/016428; this version posted March 14, 2015. The copyright holder for this preprint (which was not certified by peer review) is the author/funder, who has granted bioRxiv a license to display the preprint in perpetuity. It is made available under aCC-BY-ND 4.0 International license.

\section{Green Monkey mtDNA Bases 5092-7190}

1 gccctracaa ccaccatatt cctattcctc aatctgaact caaataccac aacccttaca 61 ctatccctya cctgaaacaa atcaccccaa ctcataccac taacaatatt cacccttata 121 tccctaggag gwttaccccc rctaaccggc ttyctaccta aatgaataac tattcaagaa 181 cttrcaataa acarcaactt ygtcatcccc tccatcatag tcaycataac yctacttaac 241 ctgtacttct acatacgcct aatctacact gtctcagtat cactatttcc caccccaac 301 aacacaaaaa tgaactgaca acttgaaaac acaaaaccca cacccctcac ccccacactc 361 accatcattt ctactctcct actaccaatc acccccctaa tcctaactat tccctagaaa 421 tttaggttaa ataagaccaa gagccttcaa agcccttagt aagtagacca cttaatttct 481 gaaacatata aggactgcaa aaacctactc tgcatcaatt gaacgcaaat caaccactt 541 aattaagcta agcccctact agaccaatgg gactcaaacc cataaaaatt tagttaacag 601 ctaaacaccc taatcaactg gctttgatcc acttctcccg ccacgagaaa aaaaggcggg 661 agaagccccg gcagaaactt aaaactgctc ctttaaactt gcaatttaac atgaaaatca 721 cctcggggct ggcaaaaaga ggatcagacc tctgtcttca ggtttacagc ctaatgctta 781 ctcagccatt ttacccttcc tccacccatg ttcattaatc gttgactctt ttcaacaaac 841 cataaagaca tcggaactct atacctacta ttcggtgcat gagctggaat cataggtaca 901 gctctaagcc ttctcattcg agctgaatta ggccaacccg gtagtttact aggcagtgac 961 catatctata atgtcattgt aacagcccat gcatttatta taattttctt catagttata 1021 cccattataa tcggggggtt cgggaactga ctagtaccct tgataattgg tgctcctgac 1081 atagcatttc cccgtctaaa taatatgagc ttctgacttc ttcccccctc cttcctgctg 1141 ctaatggcat caaccataat cgaggctggc gctggaacag gttgaacagt atacccccc 1201 ttagcaggaa acctctctca cccaggggcc tccgtagact tagttatttt ctccctccac 1261 ctagcaggag tttcctctat cctgggggct atcaacttca ttaccaccat tatcaacatg 1321 aagccccccg ccatatccca gtatcaaacc ccgttatttg tctgatctgt cctaatcaca 1321 aagcccccg ccatatccca gtatcaaacc ccgttatttg tctgatctgt cctaatcaca 1441 gaccgcaacc tcaacactac cttctttgat cctactggag ggggagacc tatcctatac

1501 caacacctat tttgattctt tggtcaccct gaagtctaca tcctcattct ccccgggttc

1561 ggaataatct cccacatcgt aacttactac tccgggaaga aagagccatt tggatatata 1621 ggtataacct gggctataat gtcaatcggg ttcctaggat ttattgtatg agcccatcat 1681 atatttacag tgggtataga tgtggacaca cgggcctact ttacctctgc tactataatc 1741 attgcaattc ctactggagt taaagttttc agctgacttg ctacacttca tggaggcaat 1801 atcaaatgat ctgccgcaat actttgagcc ctaggcttta tttttctatt caccatagg 1861 ggtctcaccg gtattatctt agcaaactca tccctagata ttgtactaca cgatacatac 1921 tatgttgtcg cccatttcca ctatgttttg tcaataggag ctgtttttgc cattataggg 1981 ggctttgtcc actgattcc tttattttca ggctacacat tagaccaaac ctatgccaaa 2041 gcccacttta ttattatatt cacaggcgta aatttaacct ttttccaca acacttcct

\section{Green Monkey NUMT on Chromosome 8}

1 attctaacaa ttaccgcatt tccagcactc aatctgagca caagcagtac aaccctatca

61 ttattccaca cctgaaataa accaacatga ctaacaccta taatccatta atttattat 121 ccttaggagg tttacccctg ttaggacttc tccctaaatg agttaccatc taagaactta 181 caaaaaatga gtcttattgc cccaaccatt ataaatagta taaccctact caacctatac 241 ttttacatat gtgtaattta ctccacctca gtgacaatat tccccacatc taataacata 301 aaaataaaat gatagttcaa aaacagaaag tccatattaa ccctccccc acttataatc 361 tcctctacgc tcctcttacc tatttctcca ttaacactag ctgtgatcta gaaattcagg 421 ttaaatgaga ccaatggcct tcaaagcctt tagcaagtaa attatacttc atttctgcaa 481 caaagctaag gactgcaaaa ctccactctg catcaattga acgcaaatca accactttaa 541 ttaagctaag ccctcgctag cttgatggaa ttaaacccac gaaaatttag ttaacagcta 601 aacaccctaa tcaactggct tcaatctgct tctcccaacg ctgggaaaaa aggcgggaga 661 agccccggca ggattgaagc tgctcctttg aacttcgtct gcattttcat gttgaattca 721 acatgaaaat caccttggga ctggtgaaaa gaggccttaa cttctgtctt tagatttaca 781 gtttaatgct tactcagcca ttttaccttt ttcactccac ttacgttcat caaccgttga 841 ttgttttcag ctaaccacaa agacattgca acatcatact tactattctg agcatgaaca 901 gggatggcgg gcacagcctt aagcctcctt attcgagcag aactgggcca accagggact 961 ctgttagaag attatcaaat ttacaacgtt attgttaccg tccacgcatt tatcataatt 1021 ttctttatag ttataccaat cataatcgga ggtttcggca actgattagt ttctctcata 1081 attggcactc ccaatgtggc atttccccaa ataaataaca tgattttctg acttcttccc 1141 cagacccceg cctgccccgt ttcctaccat gatttgcgtc ctcaatggta gaggctggcg 1201 gcgggacccg ctggacagtt tatcctccct taacaggaaa ggtaacacgc aggatcctct 1261 gtggacccga tcatcttctc acttaattta gcagacatct cttctattct aggagctgtt

1321 aattttacta ccacaatcat gaatccccca gtcatatccc aacatcacac accctcttc 1381 gcctgatcag tcctaattac agcagttcta cttctttctc ttccagtcct agcggccggc 1441 attactatac tattaactga ccataatctc aacactactt tgtttgacc agctggtaga 1501 ggtgaatcta tcctgtaaca acaattattc tgatttttg gccaccctga agtctatatc 1561 cttatcctgc aaggcttctg gataatctcc cacgtcgtaa cacagtattg tggaaaaaag 1621 gaaccatttg tgtacatggg catagaatga gccatagtat caattggttt cttaggattt 1681 atcatatggg ctcaccacat acttacagta ggaatagatg tacatacacg agcatacttc 1741 acctctgcca ctatgattat tgcaattatt gccctcccca ctggcgtcaa agtcttcagc 1801 tggttagctt cactacatgg cagcaacatc aaatccccac aattctttga gccetgggat 1861 ttatatccct ttttacatta agaggtctga ccagcattgt actagctaac tcatcactag 1921 atattgtctt gcatgacaca tattatgtta tagcccattt caattacatc ttatccatag 1981 gaggcgtatt tgctattaca ggaggctttg tccactgatt tcccctattc tcaggttaca 2041 tacttagtca gacctatgct aaaattcatt ttaccatcat gtttacaggt gttaatttta 2101 cttttttccc acagcatttc ct

Notes:

Sequences 2 \& 4 differ by:

150 base mutations and 14 small insertions/deletions (not illustrated) which gives an approximate mutation/base rate of $7.6 \%$ 